\title{
Transient Plastic Flow and Phase Dissolution During Hot Compression of $\alpha / \beta$ Titanium Alloys
}

\author{
S.L. SEMIATIN, N.C. LEVKULICH, C.A. HECK, A.E. MANN, N. BOZZOLO, \\ A.L. PILCHAK, and J.S. TILEY
}

Transients in plastic flow behavior and the kinetics of dynamic dissolution of $\alpha$ particles were established via isothermal, hot compression testing of Ti-6Al-4V (Ti64) and Ti-6Al-2Sn-4Zr2Mo-0.1Si (Ti6242S). For this purpose, samples were preheated at a low subtransus temperature at which the volume fraction of $\alpha$ was $\sim 0.90$, heated at a fixed rate to one of two higher temperatures, held for a time between 0 and 900 seconds, and then upset to a 2:1 reduction using a strain rate of $0.01,0.1$, or $1 \mathrm{~s}^{-1}$. For a given alloy, test temperature, and strain rate, the flow stress decreased with increasing hold time. The observations were interpreted in terms of various models of plastic flow and microstructure evolution. The plastic-flow behavior of the two-phase microstructures was analyzed using approaches based on isostrain (upper-bound), self-consistent (SC), and isostress (lower-bound) approaches coupled with the measured (transient/ non-equilibrium) phase fractions/phase compositions. The isostrain and SC methods both provided reasonable estimates of the observed flow stresses; the isostress method greatly under-predicted the measurements. Microstructure models comprised diffusion-based analyses of the dissolution of $\alpha$ particles into the $\beta$ matrix both statically (during heating to test temperature and holding prior to deformation) and dynamically (during deformation). Static dissolution predictions showed good agreement with measurements. A comparison of static and dynamic dissolution behaviors revealed that concurrent deformation led to an enhancement of diffusion rates by a factor of approximately 8 or 4 for Ti64 and Ti6242S, respectively.

https://doi.org/10.1007/s11661-020-05673-9

(C) The Minerals, Metals \& Materials Society and ASM International 2020

\section{INTRODUCTION}

THE thermomechanical processing of metallic materials is often characterized by transients in temperature and strain rate. These variations may arise from workpiece-tooling interactions, interface friction, equipment design, etc. ${ }^{[1-3]}$ For example, the conventional forging of hot metal between cooler dies can give rise to substantial temperature decreases at the surface and within the workpiece due to so-called "die chill". The extent of heat loss is a function of the initial temperatures of the workpiece and tooling, the interface heat transfer coefficient, contact pressure and time, etc. In

S.L. SEMIATIN, A.L. PILCHAK, and J.S. TILEY are with the Air Force Research Laboratory, Materials and Manufacturing Directorate, AFRL/RXCM, Wright-Patterson Air Force Base, OH 45433-7817. Contact e-mail: sheldon.semiatin.1@us.af.mil N.C. LEVKULICH is with UES, Inc., 4401 Dayton-Xenia Road, Dayton, $\mathrm{OH}$ 45432. C.A. HECK is with the Wright-State University, Dayton, $\mathrm{OH}, 45435$. A.E. MANN is with Boeing Research \& Technology, Next Generation Metals Technology, Berkeley, MO 63134. N. BOZZOLO is with MINES ParisTech, PSL Research University, CEMEF, 06904 Sophia Antipolis Cedex, France.

Manuscript submitted November 8, 2019.

Article published online February 13, 2020 turn, the contact time depends on the type of press (or hammer), usually being relatively short or long for screw/mechanical presses and hydraulic presses, respectively. Strain-rate variations at given material points may arise from metal flow as affected by die and preform design, die chill, and equipment characteristics such as ram deceleration at the end of the stroke during forging in mechanical presses.

In contrast to die chill, die-workpiece friction tends produce localized heating at the interface whose magnitude varies with interface pressure, metal flow, etc. Two broad extremes in frictional heating are typically encountered in deformation processes. The first consists of that associated with operations such as forging, extrusion, rolling, etc.; its extent is usually mitigated by the use of lubricants. More substantial (and desirable) frictional heating forms an integral part of solid-state joining processes (SSJ) such as inertiaand linear-friction welding. ${ }^{[4-7]}$ In these latter cases, the heat generated by relative rotational or translational motion at the interface between two components to be joined results in local softening and upsetting under the action of a superimposed force normal to the interface. The compressive deformation expels impurities (contained within flash) from the interface, thereby bringing 
clean metal into contact and effecting bonding. In SSJ operations, the rate of heating is usually of the order of $10^{2}$ to $10^{3} \mathrm{~K} / \mathrm{s}\left(10^{2}\right.$ to $\left.10^{3}{ }^{\circ} \mathrm{C} / \mathrm{s}\right)$, and strain rates are generally in the range of 0.2 to $1 \mathrm{~s}^{-1}$ at the interface, but can be substantially higher $\left(\sim 10^{3} \mathrm{~s}^{-1}\right)$ in the flash. ${ }^{[8-15]}$

The simulation of deformation processes involving temperature and strain rate transients places stringent demands on the nature of constitutive relations required as part of the input material database. This information is usually obtained from nominally-isothermal, hot compression or torsion tests performed under constant strain-rate conditions. ${ }^{[16]}$ Such data cannot describe the evolution of metastable microstructural features (such as phase fraction/compositions, grain size, etc.) and concomitant plastic-flow response for large departures from nominal test conditions, however. ${ }^{[17]}$ To overcome this limitation, alternate types of mechanical tests are sometimes performed. These include "on-heating" or "on-cooling" experiments comprising preheating (and soaking) at a specified temperature, rapid heating or cooling, respectively, to another temperature, followed immediately by deformation. ${ }^{[18-25]}$ By this means, the broad effect of thermal transients on hot ductility, flow stress, etc. have been deduced.

The effect of temperature and strain rate transients on plastic flow may be expected to be pronounced for alloys with a large fraction of a second phase, e.g., $\alpha / \beta$ titanium alloys and $\gamma^{\prime}$-strengthened nickel-base superalloys. For $\alpha / \beta$ titanium alloys in particular, the ratio of the flow stress of the hcp $\alpha$ and bcc $\beta$ phases at hot working temperatures (for equivalent strain rate) is approximately $3: 1 .^{[26,27]}$ Thus, the retention of a non-equilibrium fraction of low-temperature $\alpha$ phase during rapid heating to a temperature approaching or exceeding that at which $\alpha+\beta \rightarrow \beta$ (i.e., the $\beta$ transus temperature, or $\mathrm{T}_{\beta}$ ) could be expected to produce a flow stress considerably higher than that which corresponds to equilibrium phase fractions.

The present work was undertaken to establish the quantitative effects of non-equilibrium phase fractions on plastic flow and the kinetics of the approach to equilibrium during the hot deformation of two typical $\alpha /$ $\beta$ titanium alloys, Ti-6Al-4V and Ti-6Al-2Sn-4Zr$2 \mathrm{Mo}-0.1 \mathrm{Si}$, hereafter referred to as Ti64 and Ti6242S. For this purpose, hot compression tests were conducted on samples soaked initially at a low temperature (at which there was a very large fraction of $\alpha$ ), that were then heated to the test temperature and held for various times (prior to upsetting) in order to modify the volume fractions of the two phases. Experimental stress-strain data and microstructure observations were interpreted in the context of isostrain, self-consistent, and isostress plastic-flow model ${ }^{[25,28]}$ and analyses of dynamic- $v s$ static dissolution of a metastable second phase. The present work complements a recent effort whose objective was to describe the supertransus static-dissolution kinetics of $\alpha$ under both isothermal and continuous-heating conditions using Ti64 as the program material. $^{[29]}$

\section{MATERIALS AND EXPERIMENTAL PROCEDURES}

\section{A. Materials}

Two common $\alpha / \beta$ titanium alloys, Ti64 and Ti6242S, were used to quantify transient plastic flow and second-phase dissolution during hot working. These materials also enabled the determination of the influence of solutes with markedly-different diffusivities in $\beta$ titanium (i.e., vanadium vs molybdenum) on such behaviors. The Ti64 was from the same lot as that used previously ${ }^{[29]}$; it was received in the form of $12.7-\mathrm{mm}$-diameter hot-rolled bar stock with a measured composition (in weight percent) of $6.33 \mathrm{Al}, 4.07 \mathrm{~V}, 0.19 \mathrm{Fe}$, $0.16 \mathrm{O}, 0.01 \mathrm{C}, 0.01 \mathrm{~N}, 0.0048 \mathrm{H}$, balance titanium; its $\mathrm{T}_{\beta}$ was $1261 \mathrm{~K}\left(988^{\circ} \mathrm{C}\right)$. The Ti6242S program alloy was also received as hot-rolled bar (with a diameter of 15.9 $\mathrm{mm}$ ). Its composition (in weight percent) was $5.94 \mathrm{Al}$, $1.96 \mathrm{Sn}, 3.83 \mathrm{Zr}, 1.95 \mathrm{Mo}, 0.07 \mathrm{Si}, 0.02 \mathrm{Fe}, 0.14 \mathrm{O}$, $<0.01 \mathrm{C},<0.01 \mathrm{~N}, 0.0016 \mathrm{H}$, balance titanium; and its $\mathrm{T}_{\beta}$ was $1275 \mathrm{~K}\left(1002^{\circ} \mathrm{C}\right)$.

To eliminate the majority of remnant (unspheroidized) lamellar $\alpha$ and thereby develop a microstructure of equiaxed $\alpha$ in a matrix of $\beta$, each lot of material was given an initial heat treatment comprising 4 hours at $1227 \mathrm{~K}$ $\left(954{ }^{\circ} \mathrm{C}\right.$ ) (for Ti64) or $1247 \mathrm{~K}\left(974{ }^{\circ} \mathrm{C}\right)$ (for Ti6242S), followed by furnace cooling. At the pre-soak temperature of $922 \mathrm{~K}\left(649{ }^{\circ} \mathrm{C}\right)$ used in subsequent experiments, the microstructures of Ti64 and Ti6242S thus contained equiaxed- $\alpha$ particles (dark, equiaxed phase in backscattered electron images) with an area fraction of 0.90 or 0.93 , respectively, and average (circle-equivalent) diameter of 9.52 or $10.54 \mu \mathrm{m}$, respectively (Figure 1). Furthermore, both materials had relatively weak $\alpha$-phase textures, as exhibited by 0001 pole figures determined via EBSD across the entire diametral section of each alloy (Figure 2). For these textures, the Taylor factors for axisymmetric hot deformation (assuming a ratio of critical resolved shear stresses for basal $\langle\mathrm{a}\rangle$, prism $\langle\mathrm{a}\rangle$, and pyramidal $\langle\mathrm{c}+\mathrm{a}\rangle$ slip to be 1:0.7:3) were estimated to be 4.12 (Ti64) or 3.95 (Ti6242S).

\section{B. Experimental Procedures}

Isothermal, hot compression tests were performed to determine stress-strain curves and the kinetics of dynamic dissolution for microstructures consisting of initial, non-equilibrium volume fractions of equiaxed $\alpha$.


Fig. 1-Backscattered electron images of the starting microstructures of Ti64 and Ti6242S at $922 \mathrm{~K}\left(649^{\circ} \mathrm{C}\right)$. 


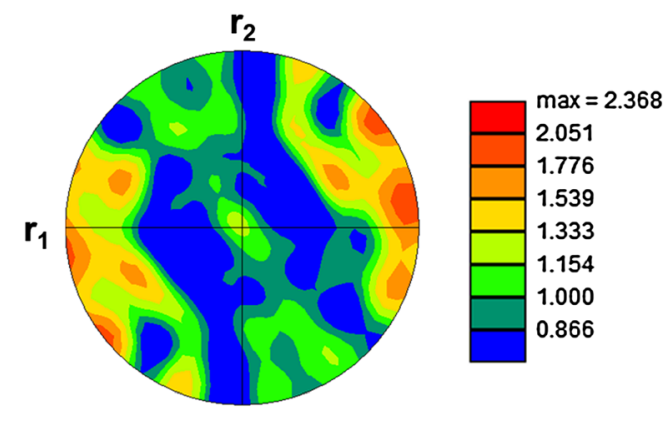

(a)

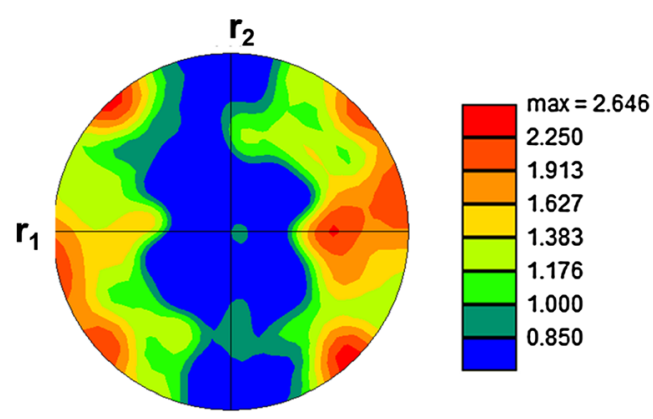

(b)

Fig. $2-(0001)_{\alpha}$ pole figures for the starting microstructures of $(a)$ Ti64 and (b) Ti6242S.

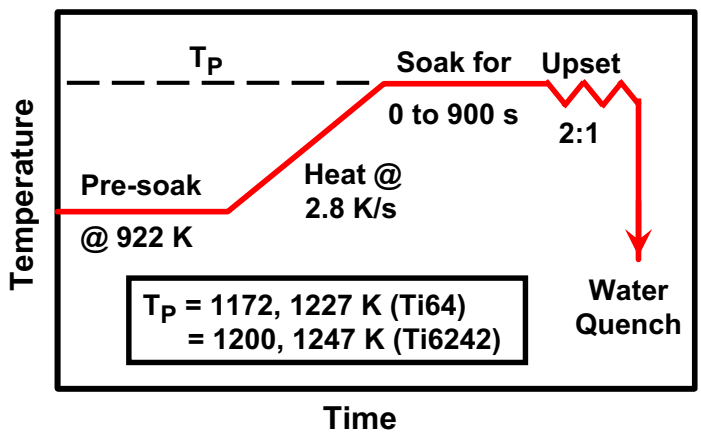

Fig. 3-Schematic illustration of the heating/deformation cycle used in the present work.

For this purpose, a number of cylindrical samples, each measuring $10-\mathrm{mm}$ diameter $\times 15-\mathrm{mm}$ height, were machined from bar stock, which had been heat treated as described in Section II-A, and then coated with a glass frit which melted and served as a lubricant during compression.

Initially, each sample and silicon-nitride compression tooling (mounted in a $250 \mathrm{kN}$ servohydraulic mechanical-testing system) were induction heated using an iron-chromium-aluminum susceptor to $922 \mathrm{~K}\left(649^{\circ} \mathrm{C}\right)$ and soaked for 10 minutes. Because the samples had been furnace cooled during initial heat treatment of the bar stock, this operation gave rise to relatively-small changes in the volume fraction of equiaxed $\alpha(\sim 0.01$ to 0.03 ), and thus served primarily to equilibrate the sample/die-stack temperature in a range for which the temperature dependence of the equilibrium $\alpha$ fraction was small for both alloys. ${ }^{[26,30]}$

Following the initial equilibration step at $922 \mathrm{~K}$ (649 ${ }^{\circ} \mathrm{C}$ ), the test sample and die stack were heated at a constant rate of $2.8 \mathrm{~K} / \mathrm{s}\left(2.8{ }^{\circ} \mathrm{C} / \mathrm{s}\right)$ to the compression test temperature, held for a time of 0 to 900 seconds, upset to a 2:1 reduction (average axial height strain $\sim 0.7$ ) at a constant true strain rate of $0.01,0.1$, or $1 \mathrm{~s}^{-1}$, and then water quenched within $\sim 1.5 \mathrm{~s}$ (Figure 3 ). The test temperatures were $1172 \mathrm{~K}$ or $1227 \mathrm{~K}\left(899^{\circ} \mathrm{C}\right.$ or 954 $\left.{ }^{\circ} \mathrm{C}\right)$ for Ti64 and $1200 \mathrm{~K}$ or $1247 \mathrm{~K}\left(927{ }^{\circ} \mathrm{C}\right.$ or $\left.974{ }^{\circ} \mathrm{C}\right)$ for Ti6242S, which corresponded to those at which the equilibrium volume fractions of $\alpha$ were equal to $\sim 0.6$ or 0.25 , respectively, for both alloys (Figure $4(\mathrm{a})^{[26,30,31]}$ ).
A second set of test samples which had been subjected to an identical heating ramp and various soak times at peak temperature prior to water quenching were also produced to document the microstructures developed during the heating transient alone.

The uniformity of test sample/die-stack temperature during the heating ramp was verified by two methods. The first utilized temperature records from thermocouples attached to the outer diameter and center locations at the mid-height of a test cylinder. These measurements revealed that the center temperature lagged the surface temperature by approximately $1.5 \mathrm{~K}\left(1.5^{\circ} \mathrm{C}\right)$, but this difference was eliminated within $\sim 2$ seconds of the instant at which the surface first reached the set-point temperature. The second, microstructure-based, method involved quantitative metallography (described below) to determine the area fraction of $\alpha$ at various locations (i.e., top, mid height, bottom) along both the central axis and outer diameter on axial cross sections of samples that had been heated to test temperature and then immediately water quenched. Such observations showed no systematic variation in area fraction and thus negligible differences in temperature upon reaching the test temperature.

Selected strain-rate jump tests $\left(0.01 \leftrightarrow 0.03 \mathrm{~s}^{-1}\right)$ were also performed for Ti64 to determine values of the strain-rate sensitivity of the flow stress $(\mathrm{m})$ and thus provide insight into the deformation mechanism at low strain rates.

Load-stroke data from the compression tests were reduced to true-stress-true strain curves assuming uniform deformation and correcting for test-machine compliance; compressive stresses and strains are reported herein as positive quantities. The neglect of friction was estimated to lead to maximum errors in flow stress of the order of 3 pct for the sample geometry and height reduction used in the present work. ${ }^{[32]}$

After testing, each sample was sectioned axially and prepared using standard metallographic procedures prior to imaging in an FEI Quanta scanning electron microscope (SEM). SEM settings consisted of an accelerating voltage of $20 \mathrm{kV}$, working distance of $10 \mathrm{~mm}$, spot size of 5 , and aperture size of $30 \mu \mathrm{m}$. In all instances, backscattered electron (BSE) micrographs were taken at magnifications of 500 to 2000 times, and the area fraction of $\alpha$ was determined by point counting 


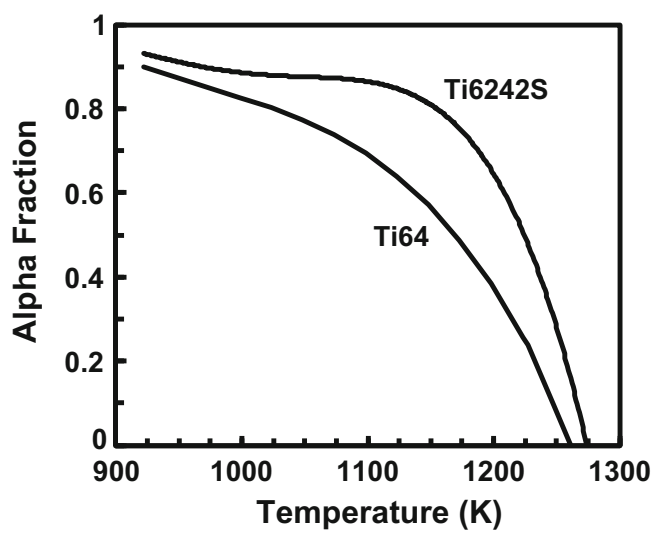

(a)

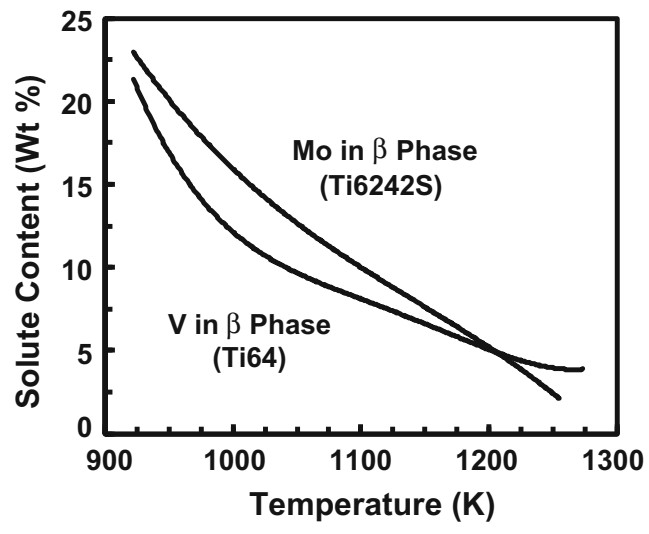

(b)

Fig. 4-Phase equilibria data forTi64 and Ti6242S: (a) Alpha fraction as a function of temperature and (b) equilibrium V, Mo solute content in $\beta$ as a function of temperature. [26,30,31] $^{-10}$

on 2 to 4 images (superimposed with $\sim 3000$ grid intersections). In BSE of $\alpha / \beta$ titanium alloys, $\alpha$ appears darker, and the matrix (transformed) phase developed during quenching (which had been $\beta$ at high temperature) is lighter. The uncertainty in area-fraction measurements was estimated to be approximately \pm 0.02 . The number of $\alpha$ particles per unit area was also determined manually for samples presoaked at $922 \mathrm{~K}$ $\left(649{ }^{\circ} \mathrm{C}\right)$ followed by water quenching as well as other selected samples. By this means, the average two-dimensional (2D) circle-equivalent diameter was estimated per the approach described in Reference 33.

Wavelength dispersive spectroscopy (WDS) was performed using a Cameca SX-100 electron microprobe to quantify the magnitude of concentration gradients developed during transient heating/deformation. This equipment was operated at an accelerating voltage of 15 $\mathrm{kV}$, beam current of $15 \mathrm{nA}$, and aperture size of $150 \mu \mathrm{m}$. Based on previous experience, ${ }^{[29}$ the reliability of the measurements for the substitutional alloying elements was estimated to be $\sim 0.2$ to $0.3 \mathrm{wt}$ pct.

\section{RESULTS}

The principal results of this investigation consisted of measurements of plastic-flow response and microstructure observations.

\section{A. Plastic-Flow Behavior}

True-stress-true strain curves for Ti64 (Figure 5) and Ti6242S (Figure 6) showed the typical dependence of flow stress on temperature and strain rate; i.e., the overall magnitude decreased with increasing temperature and decreasing strain rate. More importantly, there was also a noticeable dependence of flow stress on hold time prior to deformation for a given test temperature and strain rate. For Ti64 at $1172 \mathrm{~K}\left(899^{\circ} \mathrm{C}\right)$ and a strain rate of $0.1 \mathrm{~s}^{-1}$, for example, the initial stress (at a strain of $\sim 0$ ) decreased with increasing hold time (Figure 5(a)). As will be shown in Section III-B, flow-curve measurements for samples held at the compression temperature for 900 seconds prior to upsetting were representative of those of material with an equilibrium volume fraction of $\alpha$ and equilibrium phase compositions. As suggested by the measurements, the decrease in flow stress with increasing hold period occurred primarily for times in the range of approximately 0 to 90 seconds. A similar conclusion can be drawn from $0.1 \mathrm{~s}^{-1}$ flow curves for Ti64 at $1227 \mathrm{~K}$ $\left(954^{\circ} \mathrm{C}\right.$ ) (Figure 5(b)) and Ti6242S at both $1200 \mathrm{~K}$ $\left(927^{\circ} \mathrm{C}\right) \quad$ (Figure 6(a)) and $1247 \mathrm{~K} \quad\left(974{ }^{\circ} \mathrm{C}\right)$ (Figure 6(b)).

The effect of hold time on deformation behavior was quantified by comparing the initial stress at a strain rate of $0.1 \mathrm{~s}^{-1}$ for the various alloys/test temperatures (Table I). At the lower test temperature for each alloy (at which the equilibrium $\alpha$ fraction was $\sim 0.60$ for both materials), the 0 -s-hold initial stress was $\sim 16$ or 31 pct higher in comparison to the equilibrium initial stress for Ti64 and Ti6242S, respectively. At the higher of the two test temperatures (at which the equilibrium $\alpha$ fraction was $\sim 0.25$ for both materials), the 0 -s-hold initial stress was $\sim 32$ or $\sim 69$ pct higher in comparison to the equilibrium initial stress for Ti64 and Ti6242S, respectively. As shown by these results, therefore, the deviation from equilibrium in terms of initial flow stress was approximately twice as great for Ti6242S in comparison to Ti64. From a qualitative standpoint, this trend may be expected in view of the $\sim 6$-fold lower diffusivity in $\beta$ titanium of Mo in comparison to $\mathrm{V}^{[30,35]}$ Furthermore, the increase in the relative difference between the 0 - and 900-s hold-time flow stresses for each alloy as a function of test temperature mirrored the marked variation in the equilibrium phase fractions, and the inability of diffusion during the heating stage to maintain such fractions (Figure 4(a)).

The flow curves in Figures 5 and 6 also exhibited noticeable flow softening. The magnitude of the softening appeared to increase with increasing strain rate, a trend that may be partially associated with the overall level of flow stress and deformation-heating effects. In addition, the softening appeared to be qualitatively 


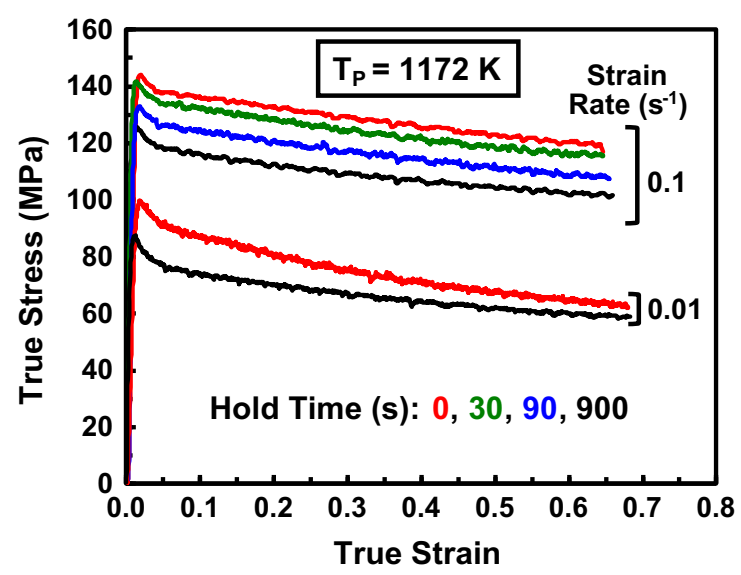

(a)



(b)

Fig. 5-True stress-true strain curves for Ti64 as a function of hold time prior to deformation and strain rate for test temperatures of (a) $1172 \mathrm{~K}\left(899^{\circ} \mathrm{C}\right)$ or $(b) 1227 \mathrm{~K}\left(954^{\circ} \mathrm{C}\right)$.

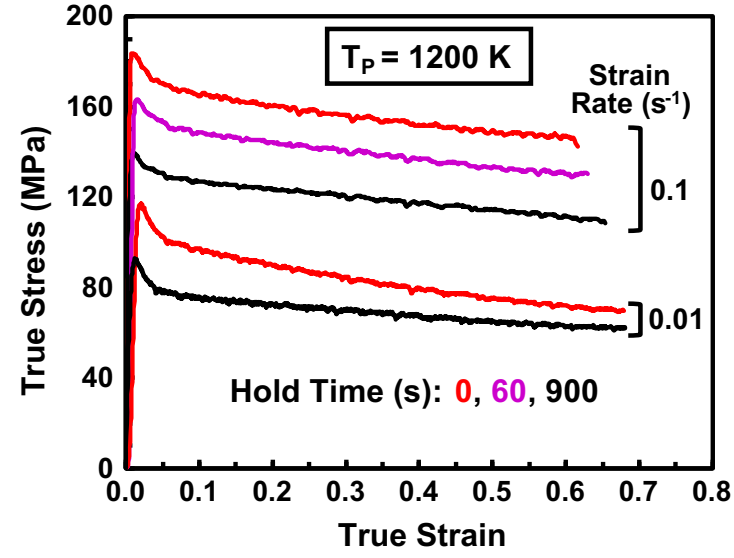

(a)

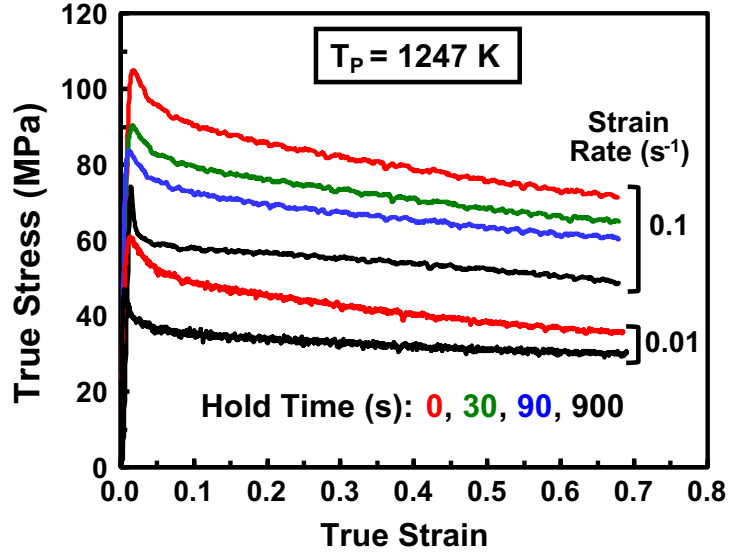

(b)

Fig. 6-True stress-true strain curves for Ti6242S as a function of hold time prior to deformation and strain rate for test temperatures of (a) $1200 \mathrm{~K}\left(927^{\circ} \mathrm{C}\right)$ or $(b) 1247 \mathrm{~K}\left(974^{\circ} \mathrm{C}\right)$.

Table I. Measurements of $\alpha$ Volume Fraction and Initial Stress at a Strain Rate of $0.1 \mathrm{~s}^{-1}$

\begin{tabular}{|c|c|c|c|c|c|}
\hline Alloy & Temp $(\mathrm{K})$ & Hold Time (s) & $\alpha$ Fraction Before Deformation & $\alpha$ Fraction After Deformation & Initial Stress $(\mathrm{MPa})$ \\
\hline Ti64 & 1172 & 0 & 0.735 & 0.67 & 147 \\
\hline Ti64 & 1172 & 900 & 0.555 & 0.56 & 127 \\
\hline Ti64 & 1227 & 0 & 0.52 & 0.36 & 86 \\
\hline Ti64 & 1227 & 900 & 0.26 & 0.26 & 64 \\
\hline Ti6242S & 1200 & 0 & 0.77 & - & 187 \\
\hline Ti6242S & 1200 & 900 & 0.64 & 0.63 & 142.5 \\
\hline Ti6242S & 1247 & 0 & 0.66 & 0.485 & 110 \\
\hline Ti6242S & 1247 & 900 & 0.275 & 0.28 & 65 \\
\hline
\end{tabular}

similar irrespective of hold time for a given alloy, test temperature, and strain rates of 0.1 and $1 \mathrm{~s}^{-1}$. This latter behavior appears to be unusual in light of the hold-time dependence of microstructure/phase composition at the onset of deformation and possible differences in the subsequent evolution of such characteristics due to dynamic dissolution. Hold time and subsequent dynamic dissolution did not appear to affect the deformation mechanism, however, as indicated by m-value results for Ti64 compressed in the strain rate range of 0.01 to $0.03 \mathrm{~s}^{-1}$ (Figure 7). For hold times of both 0 and 900 seconds, $m$ varied negligibly with strain and maintained a value of $\sim 0.26$, indicative of deformation controlled by a dislocation glide/climb 
mechanism. ${ }^{[34]}$ The sources of flow softening are discussed further in Section IV.

\section{B. Microstructure Observations}

BSE images and accompanying point-counting data provided quantitative insight into the extent of both static dissolution (during heating/holding) and dynamic dissolution (during deformation). For example, micrographs for Ti64 samples heated to $1227 \mathrm{~K}\left(954{ }^{\circ} \mathrm{C}\right)$ (Figure 8) showed substantial reductions in the amount of equiaxed $\alpha$ relative to that at the initial temperature of $922 \mathrm{~K}\left(649^{\circ} \mathrm{C}\right)$ (Figure 1(a)). In particular, the images indicated a noticeable amount of static dissolution during both the heating cycle ( 0 -s hold time upon



Fig. 7-Dependence of the strain-rate sensitivity ( $m$ value) as a function of strain and initial hold time for Ti64 jump tests at $1227 \mathrm{~K}$ $\left(954^{\circ} \mathrm{C}\right)$ and alternating strain rates of 0.01 and $0.03 \mathrm{~s}^{-1}$. reaching the peak temperature $\mathrm{T}_{\mathrm{p}}$, Figure $8(\mathrm{a})$ ) as well as during additional hold time at $\mathrm{T}_{\mathrm{p}}$ (Figures $8(\mathrm{~b})$ and (c)). Dynamic dissolution for a sample heated to $\mathrm{T}_{\mathrm{p}}$, held 0 second, and then upset to a 2:1 reduction was apparent via comparison of Figures 8(d) and (a). Micrographs for $\mathrm{T}_{\mathrm{p}}=1172 \mathrm{~K}\left(899^{\circ} \mathrm{C}\right)$ were similar, albeit the overall amount of dissolution was lower.

The BSE images for Ti64 were also useful in providing qualitative insight into chemical concentration gradients in the $\beta$ matrix that evolved during both static and dynamic dissolution. For instance, the matrix of the sample heated to $\mathrm{T}_{\mathrm{p}}=1227 \mathrm{~K}\left(954^{\circ} \mathrm{C}\right)$, held 0 second, and then water quenched (Figure 8(a)) exhibited a core that was lighter than surrounding "mantle" regions which imaged gray. Such differences in "Z-contrast" $(Z \equiv$ atomic number) were associated with the segregation of heavier and lighter alloying elements, respectively, in the $\beta$ matrix between adjacent, dissolving $\alpha$ particles. For Ti64, the principal element resulting in such concentration gradients was vanadium. $Z$-contrast differences (and associated concentration gradients) tended to decrease with increasing (static) hold time (Figure 8(b)), and were completely eliminated for a 900-second hold time (Figure 8(c)). The concentration gradients noted after short (static) hold times also persisted during subsequent compression (Figure 8(d)). Additionally, the $Z$ contrast appeared to provide local indications of the level of plastic flow in different regions of the $\beta$ matrix. In some areas, the matrix deformation appeared to be rather limited, as indicated by nearly equiaxed white/gray areas (e.g., region marked "A" in
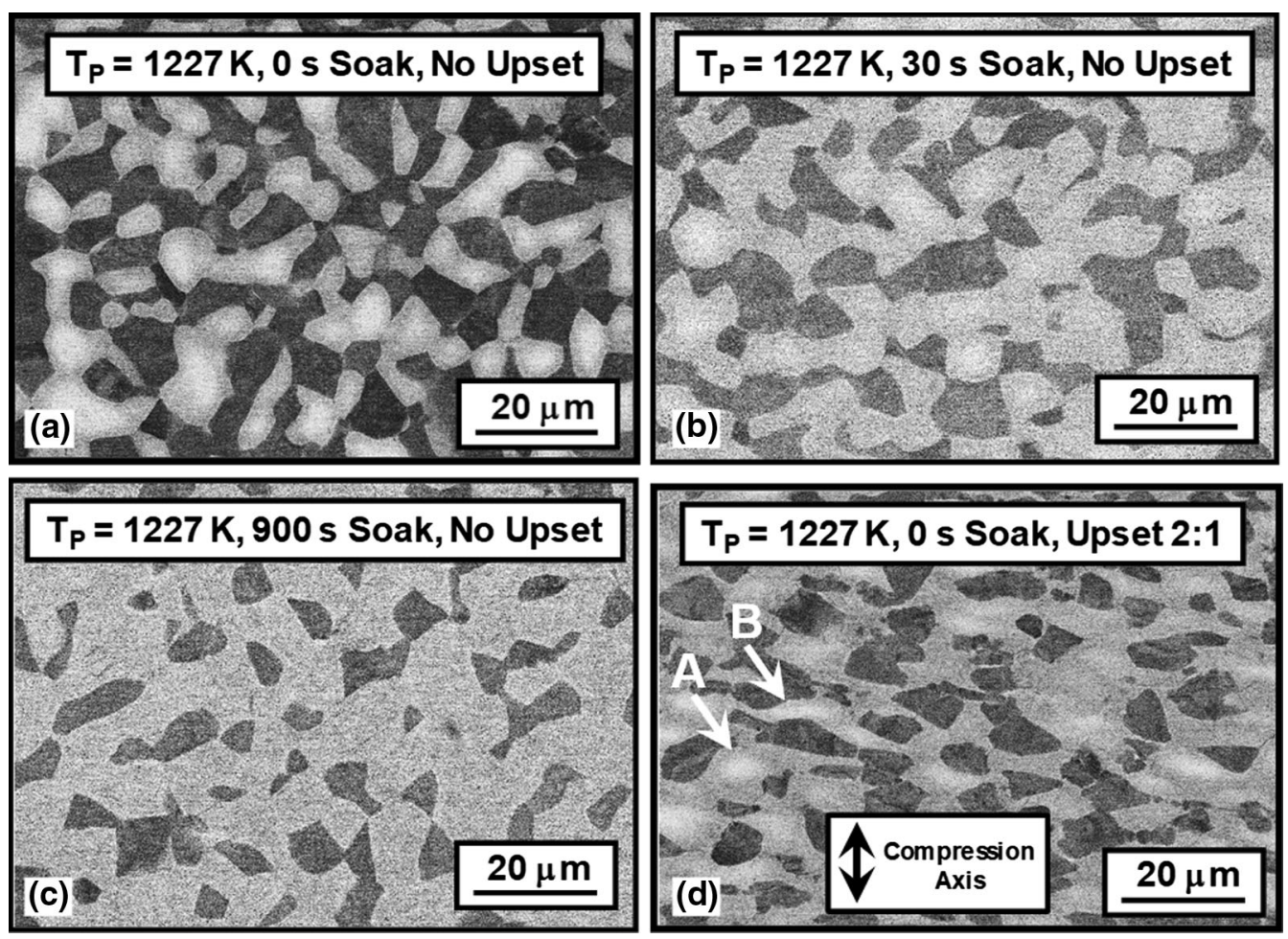

Fig. 8-BSE images of the microstructures developed in Ti64 samples heated from $922 \mathrm{~K}\left(649{ }^{\circ} \mathrm{C}\right)$ at a rate of $2.8 \mathrm{~K} / \mathrm{s}\left(2.8{ }^{\circ} \mathrm{C} / \mathrm{s}\right)$ to $1227 \mathrm{~K}$ $\left(954^{\circ} \mathrm{C}\right)$ and held statically for $(a) 0 \mathrm{~s},(b) 30 \mathrm{~s}$, or $(c) 900 \mathrm{~s}$ prior to water quenching. The image in $(d)$ is for a sample that was heated to $1227 \mathrm{~K}\left(954{ }^{\circ} \mathrm{C}\right)$, held for $0 \mathrm{~s}$, upset to a $2: 1$ reduction at a strain rate of $0.1 \mathrm{~s}^{-1}$, and then water quenched. 
Figure $8(\mathrm{~d})$ ), while it was quite extensive in others (e.g., region marked "B" in Figure 8(d)).

The concentration gradients evident in the BSE images for Ti64 were further elucidated via WDS measurements, examples of which are shown in Figure 9 for vanadium solute profiles at $1227 \mathrm{~K}\left(954{ }^{\circ} \mathrm{C}\right)$. For each of these measurements, the traverse began and ended within an $\alpha$ particle and crossed through the center of the $\beta$ matrix. For the two cases involving a 0 -s hold without or with subsequent deformation, substantial concentration gradients were observed (Figures 9(a) and (b)). Furthermore, in both of these instances, the $\beta$-phase vanadium concentration at the $\alpha / \beta$ interfaces was close to the equilibrium value (denoted as $C_{I}$ on the plots) for this temperature (Figure 4(b)). Slight deviations from the exact value of $\mathrm{C}_{\mathrm{I}}$, the apparent lack of a sharp demarcation between the concentration fields in the $\alpha$ and $\beta$ phases, and the somewhat irregular shape of the vanadium concentration field in the $\beta$ phase can be ascribed to several sources. These include (i) cross-contamination of the $\alpha$ and $\beta$ phases at the interface (due to the finite penetration volume of the electron beam) and (ii) the complex 3D shape of the concentration gradient in the $\beta$ matrix and uncertainty in the sectioning plane through it.

Vanadium concentration profiles for Ti64 samples held 900 seconds at $1227 \mathrm{~K}\left(954{ }^{\circ} \mathrm{C}\right)$ without or with subsequent deformation (Figures 9(c) and (d)) contrasted with those for the 0 -second hold time. In both of these later cases, the composition was uniform and equal approximately to $\mathrm{C}_{\mathrm{I}}$ throughout the entire $\beta$ matrix, thus indicating that chemical equilibrium had been reached by 900 seconds.

Microstructure observations (Figure 10) and corresponding WDS measurements (Figure 11) for Ti6242S were similar to those for Ti64. The major differences comprised a slightly-higher degree of $\mathrm{Z}$ contrast in the matrix associated with the segregation of molybdenum (whose atomic number is much greater than that of vanadium) and more pronounced composition gradients per se. The latter effect was likely the result of the lower diffusivity of molybdenum (compared to vanadium) in $\beta$ titanium solid solutions. Despite these differences, noticeable static and dynamic dissolution were evident as shown by a comparison of Figures 10(a) through (c) and (a) $v s$ (d), respectively, for $\mathrm{T}_{\mathrm{p}}=1247 \mathrm{~K}$. Moreover, Figures 10(c) vs (e) showed similar microstructures for samples soaked 900 seconds without or with subsequent deformation; the apparent absence of chemical segregation after 900 seconds precluded visualization of the deformation within the $\beta$, however. In addition, the WDS results for Ti6242S revealed that chemical heterogeneity noted for short dwell time without or with deformation (e.g., Figure 11(a)) had indeed been eliminated at this $\mathrm{T}_{\mathrm{p}}$ after a 900 -second hold (not shown) or

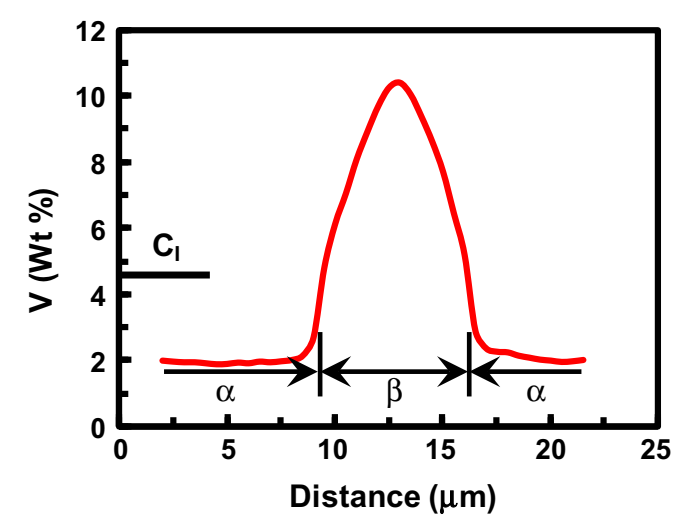

(a)

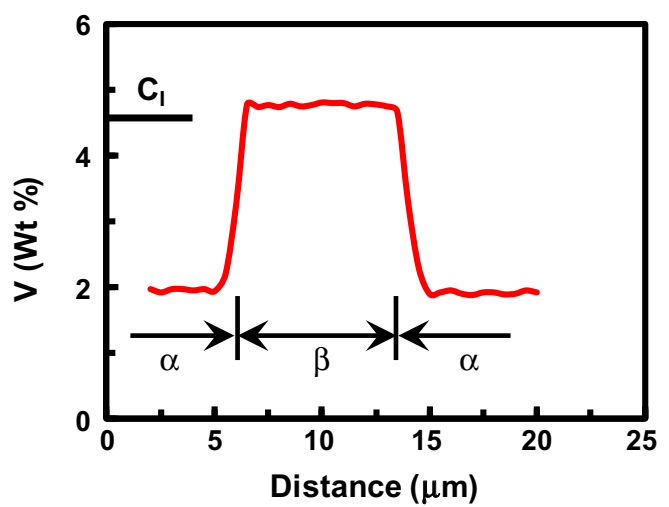

(c)

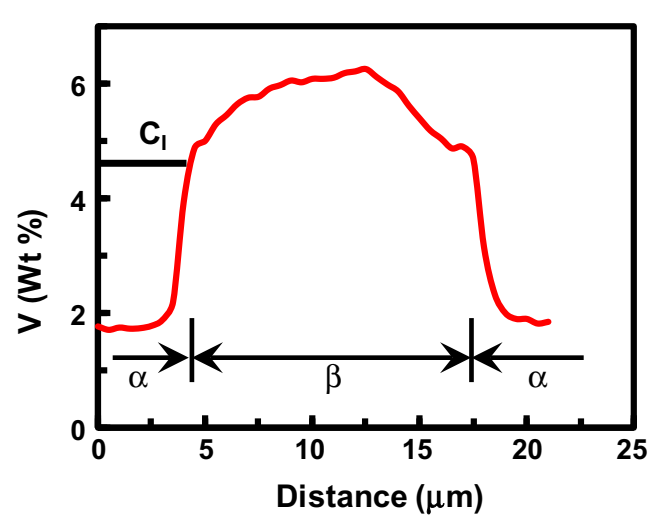

(b)

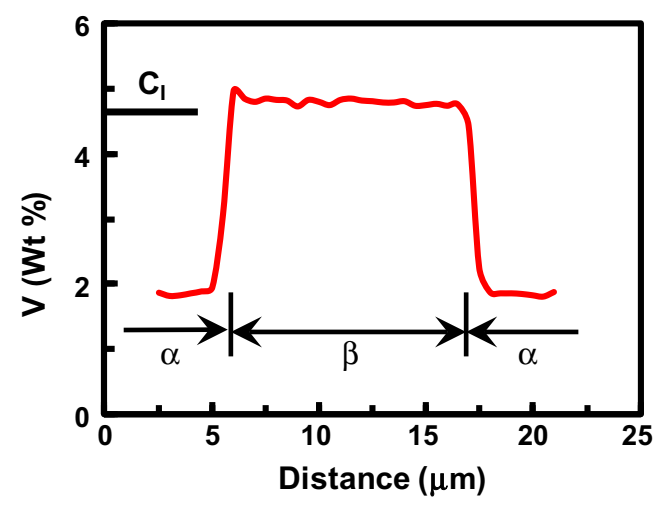

(d)

Fig. 9-WDS measurements of vanadium concentration profiles for Ti64 samples heated from $922 \mathrm{~K}\left(649{ }^{\circ} \mathrm{C}\right)$ at a rate of $2.8 \mathrm{~K} / \mathrm{s}\left(2.8{ }^{\circ} \mathrm{C} / \mathrm{s}\right)$ to $1227 \mathrm{~K}\left(954{ }^{\circ} \mathrm{C}\right)$, held for $(a, b) 0 \mathrm{~s}$ or $(c, d) 900 \mathrm{~s}$. Subsequently, the samples were $(\mathrm{a}, \mathrm{c})$ immediately water quenched or (b, d) upset to a $2: 1$ reduction at a strain rate of $0.1 \mathrm{~s}^{-1}$ and then water quenched. 

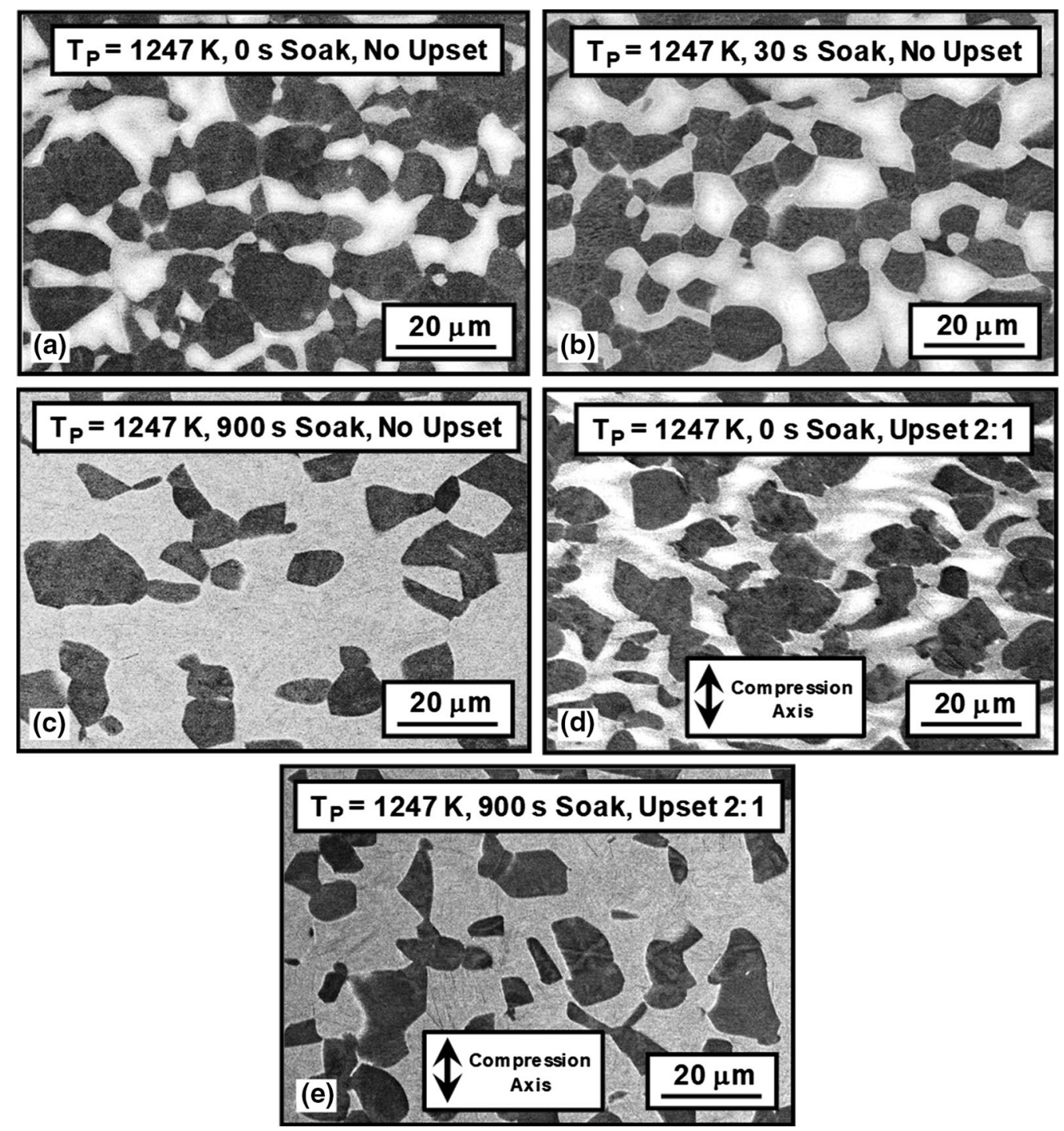

Fig. 10-BSE images of the microstructures developed in Ti6242S samples heated from $922 \mathrm{~K}\left(649{ }^{\circ} \mathrm{C}\right)$ at a rate of $2.8 \mathrm{~K} / \mathrm{s}\left(2.8{ }^{\circ} \mathrm{C} / \mathrm{s}\right)$ to $1247 \mathrm{~K}$ $\left(974{ }^{\circ} \mathrm{C}\right)$ and held statically for $(a) 0 \mathrm{~s},(b) 30 \mathrm{~s}$, or $(c) 900 \mathrm{~s}$ prior to water quenching. The images in $(d, e)$ are for samples that were heated to $1247 \mathrm{~K}\left(974{ }^{\circ} \mathrm{C}\right)$, held for (d) $0 \mathrm{~s}$ or (e) $900 \mathrm{~s}$, upset to a $2: 1$ reduction at a strain rate of $0.1 \mathrm{~s}^{-1}$, and then water quenched.

a 900-second hold followed by hot deformation (Figure 11(b)).

Quantitative measurements of the volume fractions of $\alpha$ verified the broad conclusions drawn from the BSE micrographs and WDS data for Ti64 and Ti6242S (Table I). For all instances shown in the table, the long hold time (900 seconds) led to fractions of $\alpha$ which were essentially identical before and after deformation and equal to those expected from the phase equilibria summarized in Figure 4(a). By contrast, the values of $\alpha$ fraction for a hold time of 0 second were considerably greater both before and after deformation than those for the corresponding 900-second hold Ti64 and Ti6242S samples. For these non-equilibrium cases, the degree of static dissolution during heating can thus be ascertained by comparison of the quoted preheated-alone values to those at the initial soak temperature $(0.90$ for Ti64 and 0.93 for Ti6242S) and the equilibrium values for the specific alloy and test temperature. Likewise, the degree of dynamic dissolution was mirrored by the reduction in $\alpha$ fraction relative to the corresponding preheated-alone condition.

BSE images for Ti6242S samples deformed after a 0 -second hold time in conjunction with corresponding compression-direction EBSD inverse pole figure (ipf) maps (e.g., Figure 12) provided additional insight into deformation within both the matrix phase and the $\alpha$ particles. In the EBSD ipf maps, $\alpha$ orientations within the matrix (comprising an extremely fine, martensitic structure after quenching to room temperature) could not be indexed and thus are shown as black. As for Ti64, the molybdenum-rich, white regions in the matrix in the Ti6242S BSE image (Figure 12(a)) exhibited a range of degrees of deformation as evidenced by the various aspect ratios. Similarly, a number of the individual $\alpha$-phase constituents exhibited gradations in color or intra-particle $(\alpha / \alpha)$ boundaries, suggestive of measurable local deformation, in the corresponding EBSD ipf map 

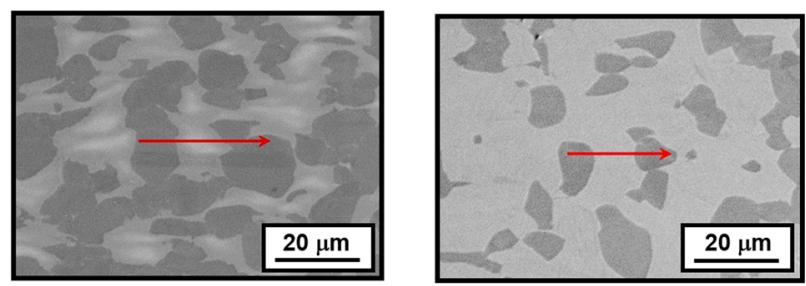

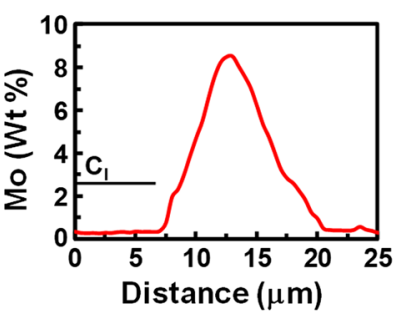

(a)

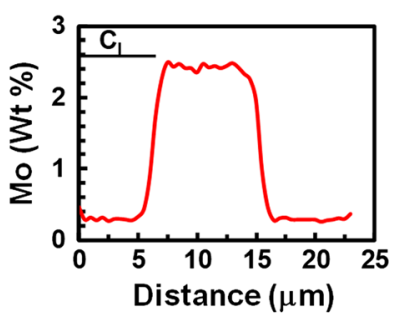

(b)
Fig. 11-BSE micrographs and corresponding WDS measurements of molybdenum concentration profiles for Ti6242S samples heated from $922 \mathrm{~K}\left(649{ }^{\circ} \mathrm{C}\right)$ at a rate of $2.8 \mathrm{~K} / \mathrm{s}\left(2.8{ }^{\circ} \mathrm{C} / \mathrm{s}\right)$ to $1247 \mathrm{~K}$ $\left(974{ }^{\circ} \mathrm{C}\right)$, held statically for $(a) 0 \mathrm{~s}$ or $(b) 900 \mathrm{~s}$, upset to a $2: 1$ reduction at a strain rate of $0.1 \mathrm{~s}^{-1}$, and water quenched.

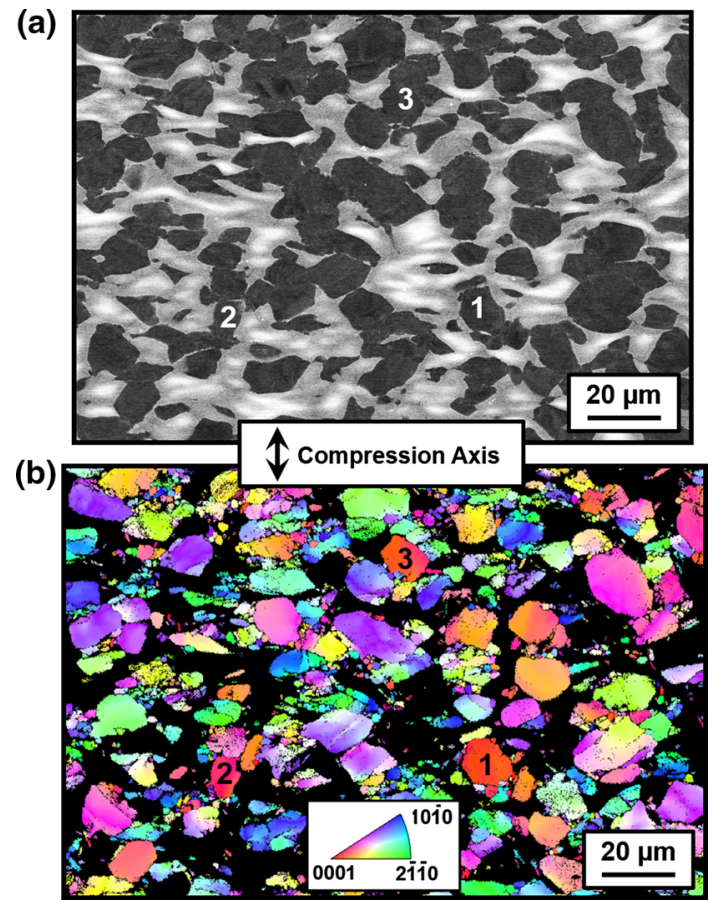

Fig. 12-(a) Deformation heterogeneity observed in a BSE image and $(b)$ the corresponding EBSD compression-direction, $\alpha$-phase inverse-pole-figure map for a Ti6242S sample heated from $922 \mathrm{~K}$ $\left(649{ }^{\circ} \mathrm{C}\right)$ at a rate of $2.8 \mathrm{~K} / \mathrm{s}\left(2.8^{\circ} \mathrm{C} / \mathrm{s}\right)$ to $1247 \mathrm{~K}\left(974{ }^{\circ} \mathrm{C}\right)$, held statically for $0 \mathrm{~s}$, and upset to a $2: 1$ reduction using a strain rate of $0.1 \mathrm{~s}^{-1}$.

(Figure 12(b)). Exceptions to this latter trend were observations for particles having a [0001] (hard) orientation parallel to the (vertical) compression direction, which are red and almost uniform in color. Several examples are labeled as 1, 2, and 3 in Figure 12(b). Their locations are also indicated in the BSE image (Figure 12(a)). Detailed examination seemed to suggest
Table II. Number of $\alpha$ Particles per Unit Area in Ti64 Compression Samples at $1227 \mathrm{~K}$

\begin{tabular}{lcc}
\hline Strain Rate $\left(\mathrm{s}^{-1}\right)$ & Hold Time $(\mathrm{s})$ & $\mathrm{N}_{\mathrm{A}}\left(\mu \mathrm{m}^{-2}\right)$ \\
\hline (Undeformed) & 0 & 0.0105 \\
0.01 & 0 & 0.0088 \\
0.1 & 0 & 0.0108 \\
1.0 & 0 & 0.0109 \\
(Undeformed) & 900 & 0.0078 \\
0.01 & 900 & 0.0101 \\
0.1 & 900 & 0.0091 \\
1.0 & 900 & 0.0084 \\
\hline
\end{tabular}

that these particles were surrounded by equiaxed $\alpha$ with softer orientations and matrix phase whose level of deformation varied spatially. Despite the complexity of such microstructures, the $\alpha$-phase Taylor factors for the 0 -second hold, $/ 0.1 \mathrm{~s}^{-1}$ Ti6242S samples after compression (4.05 to 4.10) showed little change relative to that of the un-deformed material (3.95).

Finally, measurements of the number of particles per unit area $\left(\mathrm{N}_{\mathrm{A}}\right)$ mirrored the dissolution observations in some, but not all, cases. For Ti64 samples tested at 1227 $\mathrm{K}\left(954{ }^{\circ} \mathrm{C}\right)$ with a 0 -second hold time (Table II), for example, $\mathrm{N}_{\mathrm{A}}$ decreased during deformation at $0.01 \mathrm{~s}^{-1}$, likely an indication of the disappearance of the smallest particles in the distribution. By contrast, $\mathrm{N}_{\mathrm{A}}$ appeared to remain relatively unchanged at the two higher strain rates $\left(0.1\right.$ and $\left.1 \mathrm{~s}^{-1}\right)$ for which the amount of dissolution was less. The measurements for Ti64 samples held 900 seconds prior to deformation at $1227 \mathrm{~K}\left(954^{\circ} \mathrm{C}\right)$, at which an equilibrium volume fraction had been achieved during the hold, all appeared to show an increase in $\mathrm{N}_{\mathrm{A}}$, possibly indicating a small amount of particle fragmentation, but which was more likely a result of experimental error.

\section{DISCUSSION}

The experimental observations were interpreted in terms of various models of plastic flow and diffusion-controlled dissolution kinetics.

\section{A. Modeling of Plastic Flow}

\section{Approach}

The plastic flow of the $\alpha / \beta$ titanium alloys Ti64 and Ti6242S under transient hot-working conditions was modeled using isostrain (upper bound), isostress (lower-bound), and self-consistent (SC) approaches. Each method relied on the constitutive (stress $\sigma$-strain rate $\dot{\varepsilon}$ ) response of the individual $\alpha$ and $\beta$ phases, which were described using the engineering relation:

$$
\sigma_{\mathrm{i}}=\mathrm{k}_{\mathrm{i}} \dot{\varepsilon}_{\mathrm{i}}^{\mathrm{m}} .
$$

Here, $\mathrm{k}$ denotes the strength coefficient, $\mathrm{m}$ is the strain-rate sensitivity of the flow stress (as above), and the subscripts i refer to the $\alpha$ or $\beta$ phase. The temperature ( $\mathrm{T}$ ) and composition dependence of the strength 
coefficient(s) were taken into account by rewriting Eq. [1] as follows;

$$
\sigma_{\mathrm{i}}=\mathrm{K}_{\mathrm{i}}^{\prime} \exp \left(\mathrm{mQ}_{\mathrm{i}} / \mathrm{RT}\right) \dot{\varepsilon}_{\mathrm{i}}^{\mathrm{m}},
$$

or

$$
\sigma_{\mathrm{i}}^{\mathrm{n}}=\mathrm{K}_{\mathrm{i}} \exp \left(\mathrm{Q}_{\mathrm{i}} / \mathrm{RT}\right) \dot{\varepsilon}_{\mathrm{i}}
$$

in which $\mathrm{K}^{\prime}$ and $\mathrm{K}$ describe the composition dependence, $\mathrm{n}(=1 / \mathrm{m})$ is the stress exponent of the strain rate, $\mathrm{Q}$ is an apparent activation energy for plastic flow, and $\mathrm{R}$ is the gas constant $(8.3145 \mathrm{~J} / \mathrm{mol} \mathrm{K})$.

For the $\alpha$ and $\beta$ phases in Ti64, the various material parameters were obtained from Reference 26. These included $\mathrm{n}_{\alpha}=4.6, \mathrm{n}_{\beta}=4.2, \mathrm{Q}_{\alpha}=273 \mathrm{~kJ} / \mathrm{mol}$, and $\mathrm{Q}_{\beta}=160 \mathrm{~kJ} / \mathrm{mol}^{\left[{ }^{[26]}\right.}$ The coefficient $\mathrm{K}_{\alpha}$ (when stress is expressed in the units of $\mathrm{MPa}$ ) was taken to be a function of the Al concentration in the $\alpha$ phase (in weight percent, w/o), i.e.,

$$
\log _{10} \mathrm{~K}_{\alpha}=0.37 \times \mathrm{Al}-3.375 \text {. }
$$

The value of $\mathrm{K}_{\beta}$ was a function of the so-called vanadium equivalent, $\mathrm{V}_{\mathrm{eq}}$ in the $\beta$ phase:

$$
\begin{aligned}
& V_{\mathrm{eq}}=(1 \times \mathrm{w} / \mathrm{o} \mathrm{V})+(0.27 \times \mathrm{w} / \mathrm{o} \mathrm{Al}) \\
& \log _{10} \mathrm{~K}_{\beta}= 0.000718 \mathrm{~V}_{\mathrm{eq}}^{3}-0.0316 \mathrm{~V}_{\mathrm{eq}}^{2} \\
&+0.555 \mathrm{~V}_{\mathrm{eq}}-1.483 .
\end{aligned}
$$

Per Reference 26, the composition of $\alpha$ was assumed to be independent of temperature (i.e., Ti-7.2Al-2.1V), and the average composition of the $\beta$ phase was derived using a mass balance based on the instantaneous volume fraction of $\alpha\left(f_{\alpha}\right)$ and the overall alloy composition.

The material coefficients for Ti6242S were identical to those for Ti64 except for the inclusion of an aluminum-equivalent composition (used for $\mathrm{K}_{\alpha}$, Eq. [4]) and a modified form of $\mathrm{V}_{\text {eq }}$ (used to determine $\mathrm{K}_{\beta}$ in Eq. [5b]) needed to account for the additional alloying elements, i.e., ${ }^{[27]}$

$$
\begin{aligned}
\mathrm{Al}_{\mathrm{eq}}= & (1 \times \mathrm{w} / \mathrm{o} \mathrm{Al})+((1 / 3) \times \mathrm{w} / \mathrm{o} \mathrm{Sn}) \\
& +((1 / 6) \times \mathrm{w} / \mathrm{o} \mathrm{Zr}) \\
\mathrm{V}_{\mathrm{eq}}= & (0.27 \times \mathrm{w} / \mathrm{o} \mathrm{Al})+(0.3 \times \mathrm{w} / \mathrm{o} \mathrm{Zr}) \\
& +(2 \times \mathrm{w} / \mathrm{o} \mathrm{Mo})+(13 \times \mathrm{w} / \mathrm{o} \mathrm{Si})
\end{aligned}
$$

As for Ti64, the composition of $\alpha$ in Ti6242S was assumed to be independent of temperature (i.e., Ti-6.5Al-2Sn-4Zr-0.35Mo-0.1Si), and the average composition of the $\beta$ phase was derived using a mass balance based on $\mathrm{f}_{\alpha}$ and the overall alloy composition.

In conjunction with the above constitutive relations for the $\alpha$ and $\beta$ phases and quantitative microstructure measurements (i.e., phase fractions and calculated average phase compositions), the isostrain, isostress, and SC formulations were applied to obtain estimates of the initial stress and the magnitude of flow softening of the two program alloys. For the isostrain model, the strain rate in each phase was taken to be the same as the applied (macroscopic) strain rate, and the aggregate flow stress was calculated as a rule-of-mixtures (volume-fraction-weighted) average of the flow stresses of the two phases determined from the phase constitutive relations. For the isostress method, the phase constitutive relations (with the flow stresses set equal to each other) and the rule-of-mixtures (aggregate) flow stress expression yielded two equations in two unknowns (the strain rate in each phase) whose solution provided the phase/aggregate flow stress. Last, SC predictions of the aggregate flow stress were determined based on $\mathrm{f}_{\alpha}$, the calculated values of $\mathrm{k}_{\alpha}$ and $\mathrm{k}_{\beta}$, and the nomogram in Figure 13; the latter was derived in Reference 26 for an average $\mathrm{m}$ value for the two phases of 0.23 . From this plot, an aggregate strength coefficient $(\mathrm{k})$ and thence flow stress $\left(\mathrm{k} \dot{\varepsilon}^{\mathrm{m}}\right)$ was determined. SC nomograms for the ratios of the strain rates in the individual phases were also derived in Reference 26, but are not shown here for brevity.

\section{Comparison of measurements and predictions}

Predictions of initial flow stress, strain-rate ratio, and degree of flow softening due to dynamic dissolution were compared to experimental observations for experiments performed at $0.1 \mathrm{~s}^{-1}$ with 0 - or 900 -second hold times in order to assess the applicability of the three different descriptions of plastic flow.

As expected, the isostrain and isostress formulations yielded the largest and smallest estimates, respectively, of the initial flow stress (Table III). The corresponding SC predictions lay between these bounds, but were considerably closer to the isostrain values. The isostrain and SC initial-stress predictions also showed relatively-good agreement with measurements (Table III, Figure 14). The only noticeable deviation from the observations was found for the Ti6242S experiment

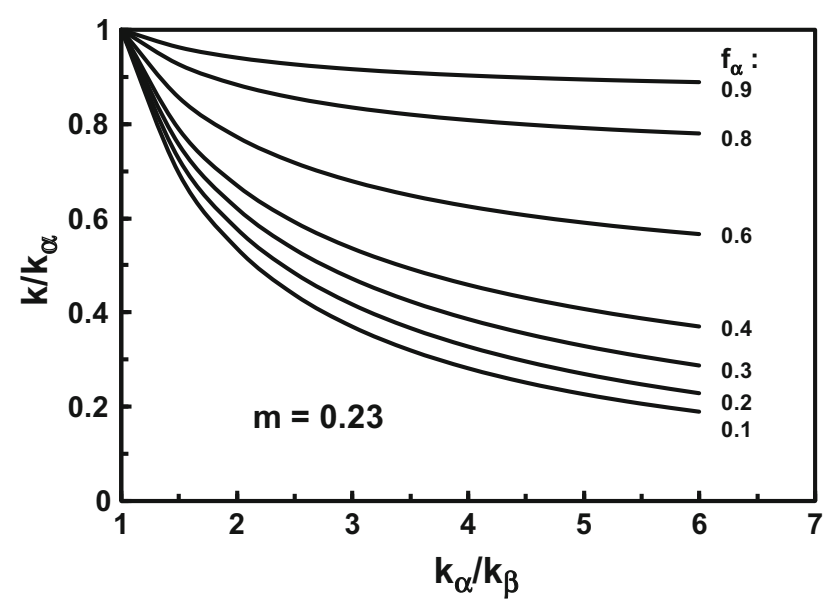

Fig. 13-Self-consistent-model nomogram for the ratio of the aggregate strength coefficient $k$ as a function of $k_{\alpha}, k_{\beta}$, and the volume fraction of $\alpha, f_{\alpha}$. 
Table III. Comparison of Measurements and Model Predictions of Initial Stress (MPa) for Ti64 and Ti6242S at a Strain Rate of $0.1 \mathrm{~s}^{-1}$

\begin{tabular}{lcccccc}
\hline Alloy & Temp $(\mathrm{K})$ & Hold Time $(\mathrm{s})$ & Measured & Isostrain Model & SC Model & Isostress Model \\
\hline Ti64 & 1172 & 0 & 147 & 157 & 149 & 103 \\
Ti64 & 1172 & 900 & 127 & 123 & 110 & 70 \\
Ti64 & 1227 & 0 & 86 & 97 & 89 & 59 \\
Ti64 & 1227 & 900 & 04 & 66 & 57 & 45 \\
Ti6242S & 1200 & 900 & 187 & 160 & 155 & 124 \\
Ti6242S & 1200 & 0 & 110 & 143 & 135 & 95 \\
Ti6242S & 1247 & 900 & 65 & 74 & 66 & 54 \\
Ti6242S & 1247 & & & & & \\
\hline
\end{tabular}

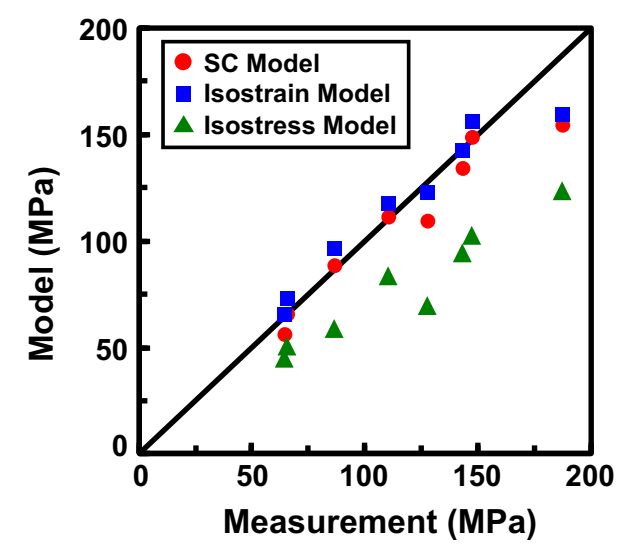

Fig. 14 - Comparison of predictions (using various modeling approaches) and measurements of the initial stress for hot compression testing of Ti64 and Ti6242S with a 0 -s or 900 -s hold time prior to upsetting at a strain rate of $0.1 \mathrm{~s}^{-1}$.

performed at $1200 \mathrm{~K}\left(927^{\circ} \mathrm{C}\right)$ with a 0 -second hold time. It may be hypothesized that the source of the error in this case is related to the texture of the $\alpha$ phase, which comprised the majority (77 pct) of the microstructure under such test conditions, but is not taken into account in the present SC formulation. The exact source of this difference warrants further investigation, however. Predictions of initial stresses from the isostress model showed relatively-large deviations from measurements in all cases (Table III, Figure 14).

Predictions of the ratio of the strain rates experienced by the two phases corresponding to the onset of plastic flow also showed considerable differences between the three modeling approaches (Table IV). Compared to the equal strain rates postulated in the isostrain formulation, SC predictions of the strain rate ratio $\left(\dot{\varepsilon}_{\beta} / \dot{\varepsilon}_{\alpha}\right)$ lay between approximately 2 (for lower temperatures/larger fractions of $\alpha$ ) and 6 (for higher temperatures, smaller fractions of $\alpha$ ). The SC trend appears reasonable in view of the $\sim 3: 1$ ratio of the flow stresses of the $\alpha$ and $\beta$ phases. Under conditions for which there is a large amount of $\alpha$, for example, accommodation of the imposed strain would likely be borne by the two phases almost equally. By contrast, under high-temperature/ low- $\alpha$-fraction conditions, the harder $\alpha$ phase would likely act like a non-deforming inclusion in the soft $\beta$ matrix. The latter conclusion is supported by the observations shown in Figures 8(d), 10(d), and 12(a) which revealed $\beta$-matrix deformation levels noticeably greater than what one may expect for an overall 2:1 height reduction in compression and $\alpha$ particles with a nearly-equiaxed shape. Microstructural insight into the strain/strain-rate inhomogeneity developed in samples held at test temperature for 900 seconds prior to upsetting (e.g., Figure 10(e)) could not be obtained due to the lack of chemical segregation within the $\beta$ matrix. Nevertheless, the nearly-equiaxed nature of the $\alpha$ particles after deformation in these instances also suggested that most of the strain was accommodated by the $\beta$ matrix.

In contrast to the $\mathrm{SC}$ predictions, the strain-rate-ratio predictions from the isostress model $(\gg 10)$ seemed to be physically-implausible when compared to the microstructure observations.

Interpretation of the large-strain plastic-flow behavior was complicated by the multiple sources of flow softening, e.g., deformation heating, texture hardening/softening, and dynamic microstructure changes per se. The apparently high-degree of strain partitioning to the $\beta$ matrix and the similarity of the $\alpha$-phase Taylor factors for Ti6242S determined before and after deformation suggested that texture hardening/softening (of $\alpha$ ) was not a major contributor to flow softening. Dynamic microstructure changes include (i) dynamic dissolution, (ii) substructure evolution within each phase, and (iii) dynamic transformation of $\alpha$ to $\beta$ which results in a reduction in the volume fraction of $\alpha$ relative to that expected from static equilibrium considerations. The latter mechanism is driven by the mechanical work arising from a reduction of aggregate flow stress during transformation which exceeds retarding influences such as the increase in Gibbs (chemical) free energy. ${ }^{[36]}$ For the present 900-second hold-time experiments, in which chemical equilibrium had been reached prior to deformation (Figures 9 and 11), there were no measurable changes in $\alpha$ fraction after deformation (Table I). Thus, dynamic transformation (and its associated softening) appeared not to have occurred in the present investigation. Possible sources of the difference between the present observations and those in the literature (e.g., dependence on alloy composition, strain rate, etc.) warrant investigation. 
The effect of dynamic dissolution on plastic flow was assessed by comparing the magnitude of flow softening in the measured 0 -second-hold-time, $0.1 \mathrm{~s}^{-1}$ flow curves (for strains between 0 and 0.7 ), each value of which was reduced by the flow softening determined for the corresponding 900-second-hold experiment in which dynamic dissolution had not occurred. (This method neglected the slightly different amounts of deformation-heating-induced softening arising from the different levels of flow stresses for each pair of 0 - and 900-second experiments.) Measured values of this so-called dissolution-related flow-softening parameter (DRFSP) are listed in Table V, and are compared to self-consistent-model predictions of DRFSP based on the initial and final volume fractions of $\alpha$ and phase compositions. In all cases DRFSP was relatively small, i.e., less than or equal to $\sim 20 \mathrm{MPa}$. For three of the four cases, the measured and predicted values varied by $\sim 10 \mathrm{MPa}$, but showed no trend with regard to one being consistently higher than the other. For the fourth case (Ti6242S at $\left.1247 \mathrm{~K}\left(974{ }^{\circ} \mathrm{C}\right)\right)$, agreement was very good. A refined model incorporating a detailed description of strain hardening and dynamic recovery within each phase may provide a better description of large-strain plastic-flow response.

\section{B. Modeling of Static VS Dynamic Dissolution}

\section{Approach}

The kinetics of the dissolution of the $\alpha$ phase during heating to/soaking at temperature and during deformation were analyzed using a method identical to that described in Reference 29. As before, the approach was similar to that of Whelan, ${ }^{[37]}$ which was modified to describe the dissolution of an aggregate of particles (rather than a single isolated particle as in the original analysis) with a size distribution that was lognormal in nature. In brief, $\alpha$ particles were assumed to be spherical, with a dissolution rate given by the following expression:

$$
\frac{\mathrm{dR}}{\mathrm{dt}}=\frac{\kappa \mathrm{D}}{2 \mathrm{R}}-\frac{\kappa}{2} \sqrt{\frac{\mathrm{D}}{\pi \mathrm{t}}}
$$

In Eq. [8], $\mathrm{R}$ is the particle radius, $\mathrm{t}$ is time, $\mathrm{D}$ is an effective diffusivity (typically associated with the rate-limiting solute). The (assumed uniform) matrix supersaturation $\kappa$ is defined as follows:

$$
\kappa=2\left(\mathrm{C}_{\mathrm{I}}-\mathrm{C}_{\mathrm{M}}\right) /\left(\mathrm{C}_{\mathrm{P}}-\mathrm{C}_{\mathrm{I}}\right)
$$

Here, $C_{I}, C_{M}$, and $C_{P}$ are the solute concentration of the matrix at the matrix-particle interface, the matrix distant from the interface, and the particle at the interface, respectively. For diffusion-controlled dissolution, $C_{I}$ and $C_{P}$ are equal to the equilibrium solute composition in the matrix immediately adjacent to the particle (Figure 4(b) for Ti64 and Ti6242S) and the particle composition, respectively. ${ }^{[37-39]}$ The composition of $\alpha$ was assumed to be uniform and constant per the present (and past ${ }^{[26,31]}$ ) experimental observations.
The present dissolution experiments and analysis differed from those performed previously ${ }^{[29]}$ in which attention had been focused on situations involving a pre-soak at a near-transus temperature (at which the equilibrium fraction of $\alpha$ was only $\sim 0.25$ ) followed by either continuous heating through the transus or an isothermal supertransus exposure. In most of the former cases, the particles were sufficiently far apart to obviate the need to consider soft impingement (overlapping) of the concentration fields between adjacent particles. In addition to the consideration of both static and dynamic dissolution, the present experiments consisted of a pre-soak at a relatively low temperature (at which the $\alpha$ fraction was $\sim 0.9$ ), thus mandating the inclusion of the following mass-balance expression in all of the calculations to account for soft-impingement:

$$
C_{M}=\frac{\left(C_{o}-f_{\alpha} C_{\alpha}\right)}{\left(1-f_{\alpha}\right)}
$$

in which Co denotes the overall alloy composition.

As before, ${ }^{[29]}$ the starting particle-size distributions (PSDs) at the pre-soak temperature, $922 \mathrm{~K}\left(649{ }^{\circ} \mathrm{C}\right)$, were taken to be lognormal with a standard deviation of $\sim 0.3$ times the normalized mean; the mean diameters at this temperature were $9.52 \mu \mathrm{m}$ (Ti64) or $10.54 \mu \mathrm{m}$ (Ti6242S). The PSDs were discretized into a series of bins, for each of which dissolution was tracked using Eqs. [8] and [9], the measured phase equilibria (Figure 4(b)), and the imposed heating rate $[2.8 \mathrm{~K} / \mathrm{s}$ $\left.\left(2.8^{\circ} \mathrm{C} / \mathrm{s}\right)\right]$. The rate-limiting solutes were taken to be vanadium (Ti64) or molybdenum (Ti6242S) with the following (baseline) diffusivities in $\beta$ titanium $^{[30,40]}$ :

$$
\begin{gathered}
\mathrm{D}_{\mathrm{V}}\left(\mu \mathrm{m}^{2} / \mathrm{s}\right)=10^{5} \exp [-17461 / \mathrm{T}(\mathrm{K})] \\
\mathrm{D}_{\mathrm{Mo}}\left(\mu \mathrm{m}^{2} / \mathrm{s}\right)=5.25 \times 10^{4} \exp [-18520 / \mathrm{T}(\mathrm{K})]
\end{gathered}
$$

Dynamic-dissolution simulations were performed in a manner similar to those for static dissolution. The only major differences consisted of (i) incorporation of estimates of the temperature rise (during the nominally-isothermal compression experiments) into the simulations and (ii) adjustment of the effective diffusivity to match the observed dissolution behavior. The latter modification enabled the determination of the quantitative effect of concurrent deformation on the enhancement of diffusion.

\section{Comparison of measurements and predictions}

Predictions of the remaining $\alpha$ fraction during cycles consisting of heating to a peak temperature $\left(\mathrm{T}_{\mathrm{p}}\right)$ of 1227 $\mathrm{K}\left(954{ }^{\circ} \mathrm{C}\right)$ (Ti64) or $1247 \mathrm{~K}\left(974{ }^{\circ} \mathrm{C}\right)$ (Ti6242S), followed by static holding at the respective temperature, showed good agreement with corresponding measurements (Figure 15). In particular, for Ti64, the measured $\alpha$ fractions at two temperatures during heating and a third during a hold at $\mathrm{T}_{\mathrm{p}}$ agreed well with static-dissolution predictions based on $\mathrm{D}=\mathrm{D}_{\mathrm{V}}$ or $\mathrm{D}=1.5 \mathrm{D}_{\mathrm{V}}$, with slightly better agreement for the latter value of diffusivity (Figure 15(a)). The efficacy of the slightly 
Table IV. Model Predictions of the Strain-Rate Ratio $\left(\dot{\varepsilon}_{\beta} / \dot{\varepsilon}_{\alpha}\right)$ for Ti64 and Ti6242S (Macroscopic Strain Rate $\left.=0.1 \mathrm{~s}^{-1}\right)$

\begin{tabular}{lccrr}
\hline Alloy & Temp $(\mathrm{K})$ & Hold Time $(\mathrm{s})$ & SC Model & Isostress Model \\
\hline Ti64 & 1172 & 0 & 2.1 & 41 \\
Ti64 & 1172 & 900 & 3.2 & 133 \\
Ti64 & 1227 & 0 & 2.9 & 84 \\
Ti64 & 1227 & 900 & 6.3 & 173 \\
Ti6242S & 1200 & 0 & 1.8 & 16 \\
Ti6242S & 1200 & 900 & 2.3 & 41 \\
Ti6242S & 1247 & 0 & 2.1 & 27 \\
Ti6242S & 1247 & 900 & 4.9 & 122 \\
\hline
\end{tabular}

Table V. DRFSP Comparisons for Ti64 and Ti6242S (0-second Hold Time, Strain Rate $\left.=0.1 \mathrm{~s}^{-1}\right)$

\begin{tabular}{lccc}
\hline Alloy & Temp (K) & Measured DRFSP (MPa) & SC Model DRFSP (MPa) \\
\hline Ti64 & 1172 & 1.5 & 12 \\
Ti64 & 1227 & 10.5 & 19 \\
Ti6242S & 1200 & 9.5 & 0 \\
Ti6242S & 1247 & 23 & 22 \\
\hline
\end{tabular}

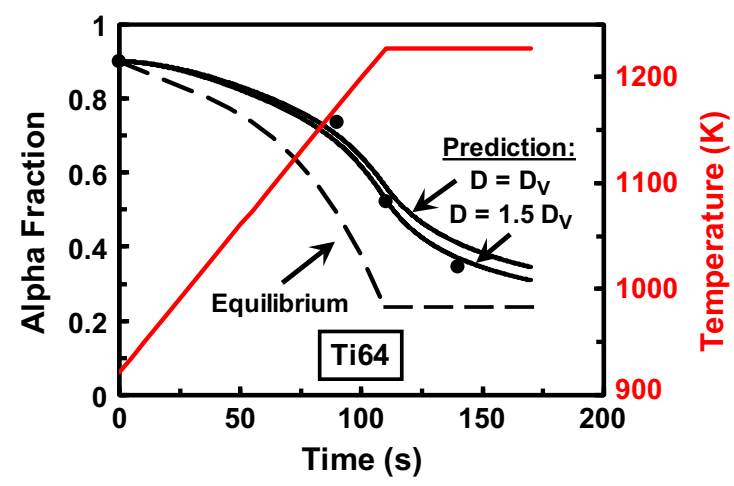

(a)

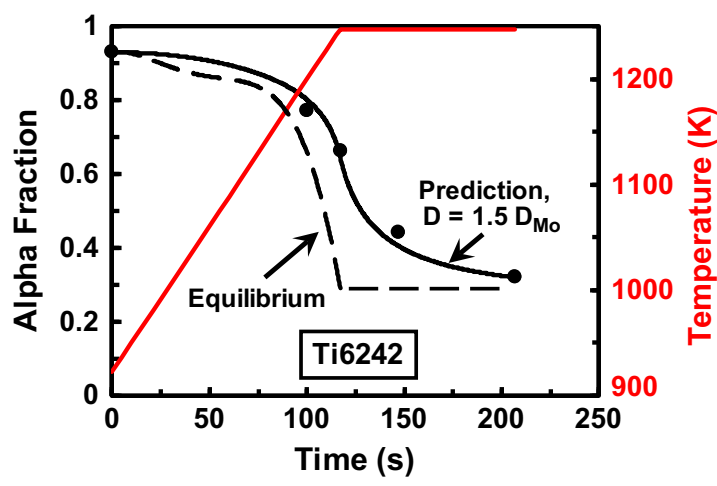

(b)

Fig. 15-Comparison of simulation predictions (solid lines) and measurements (data points) for static dissolution of the $\alpha$-phase during the indicated heating cycle (red lines): (a) Ti64 or (b) Ti6242S.

higher value of $\mathrm{D}$ mirrored that found in previous dissolution experiments conducted under conditions involving isothermal, supertransus exposure or heating through the transus. ${ }^{[29]}$ Similarly, a slightly higher value of $\mathrm{D}_{\mathrm{Mo}}$ than that found before, ${ }^{[30]}$ i.e., $\mathrm{D}=1.5 \mathrm{D}_{\mathrm{Mo}}$, gave excellent agreement with the static-dissolution measurements for Ti6242S (Figure 15(b)). The results in Figure 15 also quantify the magnitude of the deviation from equilibrium during heating and hold at $\mathrm{T}_{\mathrm{p}}$ via the comparison of measurements/predictions and the corresponding equilibrium phase fractions (broken lines).

The fitting of dynamic diffusivities using dynamic-dissolution measurements at $\mathrm{T}_{\mathrm{p}}=1227 \mathrm{~K}\left(954^{\circ} \mathrm{C}\right)(\mathrm{Ti64})$ or $1247 \mathrm{~K}\left(974{ }^{\circ} \mathrm{C}\right)(\mathrm{Ti} 6242 \mathrm{~S})$ is illustrated in Figure 16. The best fits of these data (indicated by the broken lines) were obtained using $D_{\text {dyn }}=12 D_{V}$ (for Ti64) and $D_{\text {dyn }}=6 D_{\text {Mo }}$ (for Ti6242S). Thus, the enhancement of diffusion due to concurrent deformation comprised a factor of $8(=12 / 1.5)$ for Ti64 or $4(=6 / 1.5)$ for Ti6242S. These values of dynamic diffusivity were comparable to those estimated from Fick's first law and measurements of the (V or Mo) solute concentration gradient at the $\alpha-\beta$ interface $\left.(\mathrm{dC} / \mathrm{dr})\right|_{\mathrm{R}}$ and the average particle shrinkage rate $(\mathrm{dR} / \mathrm{dt})$ at the end of deformation, i.e., $\mathrm{D}_{\mathrm{eff}} \sim-\left[\left(\mathrm{C}_{\mathrm{I}}-\mathrm{C}_{\alpha}\right)(\mathrm{dR} / \mathrm{dt})\right] /[(\mathrm{dC} /$ $\left.\mathrm{dr})\left.\right|_{R}\right]{ }^{[41]}$ Despite this internal consistency, however, the observed enhancement of diffusivity due to concurrent deformation was smaller by approximately an order of magnitude in comparison to that noted for processes such as dynamic precipitation in HSLA steels. $^{[42]}$ 


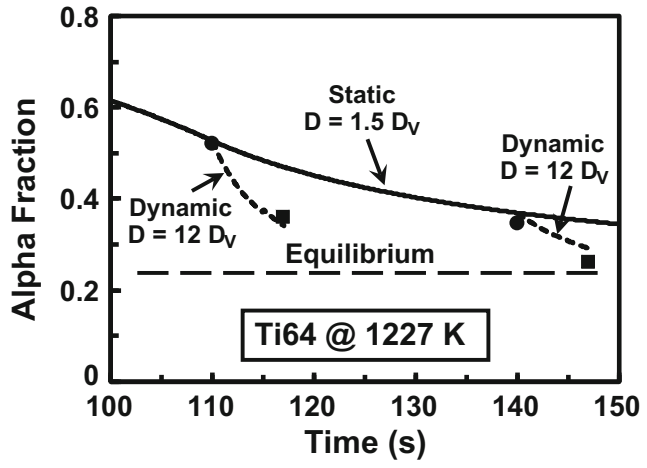

(a)

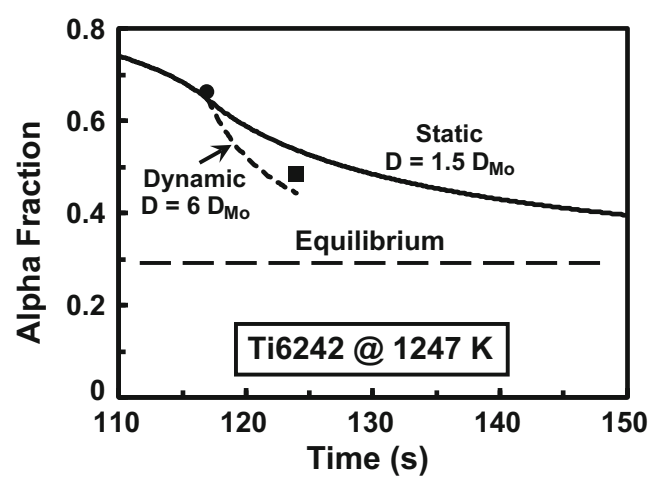

(b)

Fig. 16 - Comparison of $\alpha$-phase dissolution-simulation predictions (solid-static, broken - dynamic) and measurements (data points) for (a) Ti64 at $1227 \mathrm{~K}\left(954{ }^{\circ} \mathrm{C}\right)$ or $(b)$ Ti6242S at $1247 \mathrm{~K}\left(974{ }^{\circ} \mathrm{C}\right)$. In all cases, dynamic dissolution pertained to deformation at a strain rate of $0.1 \mathrm{~s}^{-1}$.

\section{SUMMARY AND CONCLUSIONS}

Transients in plastic-flow behavior and microstructure evolution in the $\alpha / \beta$ titanium alloys Ti64 and Ti6242S were established via experiments comprising continuous heating to a subtransus temperature $\left(\mathrm{T}_{\mathrm{p}}\right)$, holding for 0 to 900 seconds, and compression to a $2: 1$ height reduction. The following conclusions were drawn from this work:

(1) For short hold times ( $\sim 0$ to 90 seconds) following heating to $T_{p}$, flow stresses which are measurably higher than those associated with the equilibrium microstructure (attained at longer hold times) are generated due to the retention of an excess of the harder phase $(\alpha)$.

(2) The initial stress observed for compression tests on samples with a non-equilibrium or equilibrium microstructure is well predicted using either an isostrain (upper-bound) or self-consistent (SC) model in concert with appropriate phase fractions/compositions and composition-dependent constitutive descriptions for each phase. Despite the similarity in the predictions of the two approaches, however, microstructural observations utilizing BSE imaging of the concentration gradients developed in the $\beta$ matrix indicate that substantial strain-rate differences between the phases, which are precluded in the isostrain formulation, are generated during hot deformation.

(3) Levels of flow softening during hot working of samples with a non-equilibrium or equilibrium microstructure are similar. Using the equilibrium behavior as a baseline, SC model predictions of the magnitude by which non-equilibrium exceeds equilibrium flow softening (between strains of 0 and 0.7) were within $10 \mathrm{MPa}$ of measurements.

(4) Static dissolution of excess $\alpha$ phase during heating as well as holding at $T_{p}$ is well-predicted by a diffusion analysis based on the rate-limiting solute (V for Ti64, Mo for Ti6242S), provided soft impingement of $\beta$-matrix concentration fields between adjacent $\alpha$ particles is taken into account.
(5) Concurrent deformation enhances the dissolution of $\alpha$ by a factor of approximately 8 (for Ti64) or 4 (for Ti6242S).

\section{ACKNOWLEDGMENTS}

This work was conducted as part of the in-house research of the Metals Branch of the Air Force Research Laboratory's Materials and Manufacturing Directorate. The support and encouragement of the laboratory management is much appreciated. The outstanding assistance of P.N. Fagin and J.M. Shank in conducting the experiments is also gratefully acknowledged. Two of the authors were supported under the auspices of contracts FA8650-15-D-5230 (NCL) and FA8650-14-2-5800 (CAH).

\section{REFERENCES}

1. T. Altan, F.W. Boulger, J.R. Becker, N. Akgerman, and H.J. Henning: Forging Equipment, Materials, and Practices. Report MCIC-HB-03, Metals and Ceramics Information Center, Battelle's Columbus Laboratories, Columbus, OH, 1973.

2. A.M. Sabroff, F.W. Boulger, and H.J. Henning: Forging Materials and Practices, Rheinhold Book Company, New York, 1968.

3. T. Altan: Metal Forming: Fundamentals and Applications, American Society for Metals, Materials Park, OH, 1983.

4. D.D. Kautz: in ASM Handbook Volume 6A: Welding Fundamentals and Processes, ASM International, Materials Park, OH, 2011, pp. 179-85.

5. M.B. Uday, M.N. Ahmad Fauzi, H. Zuhailawati, and A.B. Ismail: Sci. Technol. Welding Joining, 2010, vol. 15, pp. 534-58.

6. A. Chamanfar, M. Jahazi, and J. Cormier: Metall. Mater. Trans. A, 2015, vol. 46A, pp. 1639-69.

7. A.R. McAndrew, P.A. Colegrove, C. Buhr, B.C.D. Flipo, and A. Vairis: Prog. Mater. Sci., 2018, vol. 92, pp. 225-57.

8. L. Wang, M. Preuss, P.J. Withers, G. Baxter, and P. Wilson: Metall. Mater. Trans. B, 2005, vol. 36B, pp. 513-23.

9. M. Maalekian: ISIJ Inter., 2008, vol. 48, pp. 1429-33.

10. L.B. Yang, J.-C. Gebelin, and R.C. Reed: Mater. Sci. Technol., 2011, vol. 27, pp. 1249-64.

11. O.N. Senkov, D.W. Mahaffey, S.L. Semiatin, and C. Woodward: Metall. Mater. Trans. A, 2014, vol. 45A, pp. 5545-61. 
12. D.W. Mahaffey, O.N. Senkov, R. Shivpuri, and S.L. Semiatin: Metall. Mater. Trans. A, 2016, vol. 47A, pp. 3981-4000.

13. R. Turner, J.-C. Gebelin, R.M. Ward, and R.C. Reed: Acta Mater., 2011, vol. 59, pp. 3792-3803.

14. C. Buhr, P.A. Colegrove, and A.R. McAndrew: J. Mater. Proc. Technol., 2018, vol. 252, pp. 849-58.

15. A.R. McAndrew, P.A. Colegrove, A.C. Addison, B.C.D. Flipo, M.J. Russell, and L.A. Lee: Mater. and Design, 2015, vol. 87, pp. 1087-99.

16. G.E. Dieter, H.A. Kuhn, and S.L. Semiatin, eds.: Handbook of Workability and Process Design, ASM International, Materials Park, OH, 2003.

17. G. Shen, S.L. Semiatin, E. Kropp, and T. Altan: J. Mater. Proc. Technol., 1992, vol. 33, pp. 125-39.

18. P.D. Nicolaou, R.E. Bailey, and S.L. Semiatin: in Handbook of Workability and Process Design, G.E. Dieter, H.A. Kuhn, and S.L. Semiatin, eds., ASM International, Materials Park, OH, 2003, pp. 68-85.

19. H.G. Suzuki and H. Fujii: ISIJ Inter., 1991, vol. 31, pp. 814-19.

20. H.G. Suzuki and D. Eylon: ISIJ Inter., 1993, vol. 33, pp. 1270-74.

21. H.G. Suzuki and D. Eylon: Mater. Sci. Eng. A, 1998, vol. A243, pp. 126-33.

22. F.F. Noecker II and J.N. DuPont: Weld. J., 2009, vol. 88 (\#1), pp. $7 \mathrm{~s}-20 \mathrm{~s}$.

23. S. Shi, J.C. Lippold, and J. Ramirez: Weld. J., 2010, vol. 89 (\#10), pp. $210 \mathrm{~s}-17 \mathrm{~s}$.

24. S.S. Babu, J. Livingston, and J.C. Lippold: Metall. Mater. Trans. $A, 2013$, vol. 44A, pp. 3577-91

25. M. Saby, E. Massoni, and N. Bozzolo: Mater. Charact., 2014, pp. 88-92.

26. S.L. Semiatin, F. Montheillet, G. Shen, and J.J. Jonas: Metall. Mater. Trans. A, 2002, vol. 33A, pp. 2719-27.

27. P. Vo, M. Jahazi, S. Yue, and P. Bocher: Mater. Sci. Eng. A, 2007, vol. A447, pp. 99-110.

28. L. Briottet, J.J. Jonas, and F. Montheillet: Acta Mater., 1996, vol. 44, pp. 1665-72.
29. S.L. Semiatin, M. Obstalecki, E.J. Payton, A.L. Pilchak, P.A. Shade, N.C. Levkulich, J.M. Shank, D.C. Pagan, F. Zhang, and J.S. Tiley: Metall. Mater. Trans. A, 2019, vol. 50A, pp. $2356-70$

30. S.L. Semiatin, T.M. Lehner, J.D. Miller, R.D. Doherty, and D.U. Furrer: Metall. Mater. Trans. A, 2007, vol. 38A, pp. 910-21.

31. R. Castro and L. Seraphin: Mém. Sci. Rev. Metall., 1966, vol. 63, pp. $1025-58$

32. S.I. Oh, S.L. Semiatin, and J.J. Jonas: Metall. Trans. A, 1992, vol. 23A, pp. 963-75.

33. S.L. Semiatin, N.C. Levkulich, A.R.C. Gerlt, E.J. Payton, J.S. Tiley, F. Zhang, R.A. MacKay, R.V. Miner, and T.P. Gabb: Metall. Mater. Trans. A, 2019, vol. 50A, pp. 2289-2301.

34. H.J. Frost and M.F. Ashby: Deformation Mechanism Maps, Pergamon Press, Oxford, 1982.

35. S.L. Semiatin, T.M. Brown, T.A. Goff, P.N. Fagin, D.R. Barker, R.E. Turner, J.M. Murry, J.D. Miller, and F. Zhang: Metall. Mater. Trans. A, 2004, vol. 35A, pp. 3015-18.

36. B. Guo, S.L. Semiatin, J. Lian, B. Sun, and J.J. Jonas: Metall. Mater. Trans. A, 2018, vol. 49A, pp. 1450-54.

37. M.J. Whelan: Metal Sci. J., 1969, vol. 3, pp. 95-97.

38. H.B. Aaron and G.R. Kotler: Metall. Trans., 1971, vol. 2, pp. 393-408.

39. H.B. Aaron and G.R. Kotler: Metal Sci. J., 1970, vol. 4, pp. 222-25.

40. S.L. Semiatin, S.L. Knisley, P.N. Fagin, F. Zhang, and D.R. Barker: Metall. Mater. Trans. A, 2003, vol. 34A, pp. $2377-86$

41. R.D. Doherty: in Physical Metallurgy, R.W. Cahn and P. Haasen, eds., North-Holland, Amsterdam, 1996, ch. 15.

42. I. Weiss and J.J. Jonas: Metall. Trans. A, 1979, vol. 10A, pp. $831-40$.

Publisher's Note Springer Nature remains neutral with regard to jurisdictional claims in published maps and institutional affiliations. 